\title{
GeNetiC EVIDENCE FOR tHe PRESENCE OF tWo SPECIES OF ONCHOCERCA FROM THE WILD BOAR IN JAPAN
}

\author{
FUKUDA M.****, OTSUKA Y.**, UNI S.***, BAIN O.***** \& TAKAOKA H.***
}

\section{Summary:}

In order to clarify the genetic differences between Onchocerca dewittei japonica, the causative agent of zoonotic onchocerciasis in Japan and a related undescribed Onchocerca sp., both parasitizing wild boar (Sus scrofa) of which the infective larval stages are indistinguishable from each other, we compared the sequences of the mitochondrial cytochrome $c$ oxidase subunit 1 (CO1) gene region from four infective larvae (recovered from experimentally infected black flies), one microfilaria, and one adult of $\bigcirc$. dewittei japonica, and from one infective larva (recovered from an experimentally infected black fly), one microfilaria, and a pool of several microfilariae of $\mathrm{O}$. sp. The length of the $\mathrm{CO} 1$ gene region was $649 \mathrm{bp}$ for all samples but there was a difference of 8.8 to $9.4 \%$ in the sequences between the two species although there were intraspecific variations of 0 to $0.5 \%$. The $\mathrm{CO} l$ sequences of $\mathrm{O}$. sp. did not correspond to any of those deposited in the databases. Our study provides evidence that $O$. dewittei japonica and $\bigcirc$. sp. are genetically different from each other.

KEY WORDS : Onchocerca, wild boar, infective larvae, Simulium, vector, zoonosis, genetic differences.

\section{INTRODUCTION}

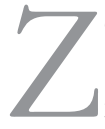

oonotic onchocersiasis is rare in humans. Only 15 cases including five cases in Japan have been reported (Beaver et al., 1989; Hashimoto et al., 1990; Takaoka et al., 1996, 2001, 2004, 2005). In all the Japanese cases, the infections were caused by Onchocerca dewittei japonica Uni, Bain \& Takaoka, 2001, a common filarial parasite of wild boar Sus scrofa Linnaeus, 1758, in Japan (Takaoka et al., 2001;

\footnotetext{
* Division of Epidemiology, Culture, and Communication, Institute of Scientific Research, Oita University, Hasama, Yufu, Oita 879-5593, Japan.

** Department of Infectious Disease Control, Faculty of Medicine, Oita University, Hasama, Yufu, Oita 879-5593, Japan.

**:* Department of Medical Zoology, Osaka City University Medical School, Osaka 545-8585, Japan.

***** Origine, Structure et Evolution de la biodiversité UMR 7205 CNRS et Muséum National d'Histoire Naturelle, Parasitologie Comparée, CP 52, 61, rue Buffon, 75231 Paris Cedex 05, France.

Correspondence : Masako Fukuda.

Tel.: +81975865702 - Fax: +81975865702

E-mail: mfukuda@med.oita-u.ac.jp
}

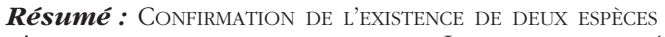
D'ONCHOCERQUES CHEZ LE SANGLIER AU JAPON PAR LES DIFFÉRENCES GÉNÉTIQUES

Pour confirmer l'existence de deux espèces d'onchocerques chez le sanglier Sus scrofa au Japon, Onchocerca dewittei japonica, agent de l'onchocercose zoonotique au Japon, et Onchocerca sp., dont l'adulte est inconnu et qui a des larves infectantes semblables, nous avons déterminé et comparé les séquences de la région du gène mitochondrial de la sous-unité 1 de la cytochrome oxydase c (CO 1) de quatre larves infectantes (récoltées chez des simulies infestées expérimentalement), une microfilaire et un adulte d'O. dewittei japonica, et d'une larve infectante /récoltée chez une simulie infestée expérimentalement), une microfilaire et un groupe de plusieurs microfilaires d'Onchocerca sp. La longueur de la région du CO 1 est de 649 bp pour tous les lots mais il y a une différence de 8,8 à 9,4\% entre les séquences des deux espèces alors que les variations intraspécifiques sont de 0 à $0,5 \%$. Les séquences de COl d'O. sp. ne correspondent à aucune de celles déposées dans les banques de données. Notre étude apporte la preuve que $\bigcirc$. dewittei japonica and $\mathrm{O}$. sp. sont génétiquement différentes.

MOTS CLÉS : Onchocerca, sanglier, larve infectante, Simulium, vecteur, zoonose, différences génétiques.

Uni et al., 2001), but the life cycle of which was unknown. Recently we have proved experimentally that six local black-fly species are suitable for the development of $O$. dewittei japonica microfilariae to the infective (third stage) larva, suggesting that Simulium species are vectors of the parasite (Fukuda et al., 2008). During this investigation, we also found microfilariae of a species of Onchocerca (longer than those of O. dewittei japonica) from wild boar and demonstrated the complete larval development of this unnamed Onchocerca sp. in female black flies. Although the adult was unknown, this filaria was tentatively assumed to be a distinct species. Interestingly, the infective larvae of these two Onchocerca species are morphologically indistinguishable (Fukuda et al., 2008).

To determine the natural vectors of $O$. dewittei japonica, accurate identification of the infective larvae of zoonotic Onchocerca species from wild-caught black flies is needed. In this study, we aimed to identify the two morphologically similar Onchocerca spp. of wild boar in Japan by differences in the sequences of the mitochondrial cytochrome $c$ oxidase subunit 1 (CO1) gene. 


\section{MATERIALS AND METHODS}

\section{SPECIMENS EXAMINED}

T Vable I shows the specimens examined in this study and their measurements. An adult worm of $O$. dewittei japonica was recovered from a wild boar, captured in Oita Prefecture, Kyushu, Japan by a licensed hunter. Species identification followed Uni et al. (2001). Five infective larvae (four O. dewittei japonica and one $O$. sp.) were recovered from the black flies experimentally infected in our previous study (Fukuda et al., 2008). Microfilariae of $O$. dewittei japonica and $O$. sp. were isolated from skin snips of wild boar in Oita. Discrimination of microfilariae between $O$. dewittei japonica and $O$. sp. followed Uni et al. (2001) and Fukuda et al. (2008).

\section{PCR AND SEQUENCING}

OF THE PARTIAL MITOCHONDRIAL CO1 GENE REGION

Total DNA was extracted from each sample with a DNeasy Blood \& Tissue Kit (QIAGEN, Hilden, Germany). The final volume of each extract was 50-100 $\mu$ l. The partial mitochondrial CO1 gene region was amplified with the primer set (CO1intF-CO1intR) described by Casiraghi et al. (2001). The reaction mixture (50 $\mu \mathrm{l})$ contained 1 x Ex Taq buffer including $2 \mathrm{mM} \mathrm{Mg}^{2+}, 200 \mu \mathrm{M}$ each of dNTPs, $0.1 \mu \mathrm{M}$ each of primers, 1.25 units of Ex Taq Polymerase (TAKARA BIO INC., Otsu, Japan), and 1-3 $\mu$ l of template DNA. PCR was performed under the following conditions: an initial denaturation at $94^{\circ} \mathrm{C}$ for $3 \mathrm{~min}$, followed by five cycles of $94^{\circ} \mathrm{C}$ for $30 \mathrm{~s}, 55^{\circ} \mathrm{C}$ for $30 \mathrm{~s}$, and $72^{\circ} \mathrm{C}$ for $1 \mathrm{~min}$ and 37 cycles of $94^{\circ} \mathrm{C}$ for $30 \mathrm{~s}, 48^{\circ} \mathrm{C}$ for $30 \mathrm{~s}$, and $72^{\circ} \mathrm{C}$ for $1 \mathrm{~min}$. PCR products were purified with a QIAquick PCR Purification Kit (QIAGEN) and directly sequenced using a BigDye Terminator v3.1 Cycle Sequencing Kit (Applied Biosystems, Foster City, CA, USA) and an Applied Biosystems 3130 Genetic Analyzer (Applied Biosystems). Sequences were deposited in DDBJ/EMBL/Gen-
Bank databases under accession numbers AB518689AB518694 (Table I).

\section{DATA ANALYSIS}

The sequences obtained were aligned with published sequences of nine Onchocerca species and two other filarial species. Using this alignment, sequences were compared, a neighbor-joining tree (Saitou \& Nei, 1987) was constructed, and bootstrap probabilities were estimated, all by MEGA 4.0.2 based on 580 bp available for comparison (Tamura et al., 2007). The Kimura 2parameter method was used for estimation of evolutionary distances in the tree. Used GenBank database accession numbers were as follows: O. dewittei japonica (AM749266, AM749267), O. eberhardi Uni \& Bain, 2007 (AM749268), O. gibsoni (Cleland \& Johnston, 1910) (AJ271616), O. gutturosa Neumann, 1910 (AJ271617), O. lupi Rodonaja, 1967 (EF521409), O. ochengi Bwangamoi, 1969 (AJ271618), O. skrjabini Ruklyadev, 1964 (AM749269), O. suzukii Yagi, Bain \& Shoho, 1994 (AM749275), O. volvulus (Leuckart, 1893) (AF015193), Thelazia callipaeda Railliet \& Henry, 1910 (AM042549) and Wuchereria bancrofti (Cobbold, 1877) (AJ271612).

\section{RESULTS}

S equences of the mitochondrial $\mathrm{CO} 1$ gene region of nine samples of $O$. dewittei japonica and $O$. sp. were determined (Table I). The length of this region in the two species was $649 \mathrm{bp}$. Interspecific nucleotide differences between $O$. dewittei japonica and $O$. sp. ranged from 8.8 to $9.4 \%$, while intraspecific variation within $O$. dewittei japonica and $O$. sp. was $0-0.5 \%$ and $0-0.3 \%$, respectively. Interspecific amino acid difference between both species was $0.9 \%$, while no intraspecific variation was found in each species. The sequences were compared with those of all the Onchocerca species available in GenBank. Table II shows the numbers of nucleotide differences over 580

\begin{tabular}{|c|c|c|c|c|c|}
\hline Onchocerca spp. & Stage of worm & No. of worm & $\begin{array}{c}\text { Body length } \\
(\mu \mathrm{m})\end{array}$ & $\begin{array}{c}\text { Body width } \\
(\mu \mathrm{m})\end{array}$ & $\begin{array}{c}\text { GenBank } \\
\text { accession no. }\end{array}$ \\
\hline \multirow[t]{6}{*}{ O. dewittei japonica } & Adult (A) & 1 & - & - & AB518689 \\
\hline & Third stage larva (L3-1) & 1 & 943.6 & 17.9 & $-{ }^{\mathrm{a}}$ \\
\hline & Third stage larva (L3-2) & 1 & $328.2^{*}$ & 20.5 & $--^{\mathrm{a}}$ \\
\hline & Third stage larva (L3-3) & 1 & $1,059.0$ & 19.5 & AB518690 \\
\hline & Third stage larva (L3-4) & 1 & $806.8^{* *}$ & 20.2 & AB518691 \\
\hline & Microfilaria (Mf) & 1 & 205.1 & 5.1 & AB518692 \\
\hline \multirow[t]{3}{*}{ O. sp. from wild boar } & Third stage larva (L3) & 1 & 964.1 & 22.6 & AB518693 \\
\hline & Microfilaria (Mf) & 1 & 364.1 & 6.7 & $-^{\mathrm{b}}$ \\
\hline & Microfilariae (Mfs) & 10 & $292.3-333.3$ & $6.2-8.2$ & AB518694 \\
\hline
\end{tabular}

* The length of one fragment. ** Total length of three fragments. ${ }^{a}$ The sequence was identical to that of $O . d . j$. (A). b The sequence was identical to that of $O$. sp. (L3).

Table I. - Measurements and stages of specimens examined in this study. 
1 O. dewittei japonica (A)

2 O. dewittei japonica (L3-1)

3 O. dewittei japonica (L3-2)

4 O. dewittei japonica (L3-3)

5 O. dewittei japonica (L3-4)

6 O. dewittei japonica (Mf)

7 O. dewittei japonica (AM749266)

8 O. dewittei japonica (AM749267)

9 O. sp. from wild boar (L3)

10 O. sp. from wild boar (Mf)

11 O. sp. from wild boar (Mfs)

12 O. eberhardi

13 O. suzukii

14 O. skrjabini

15 O. gutturosa

16 O. gibsoni

17 O. volvulus

18 O. ochengi

19 O. lupi

20 Wuchereria bancrofti

21 Thelazia callipaeda

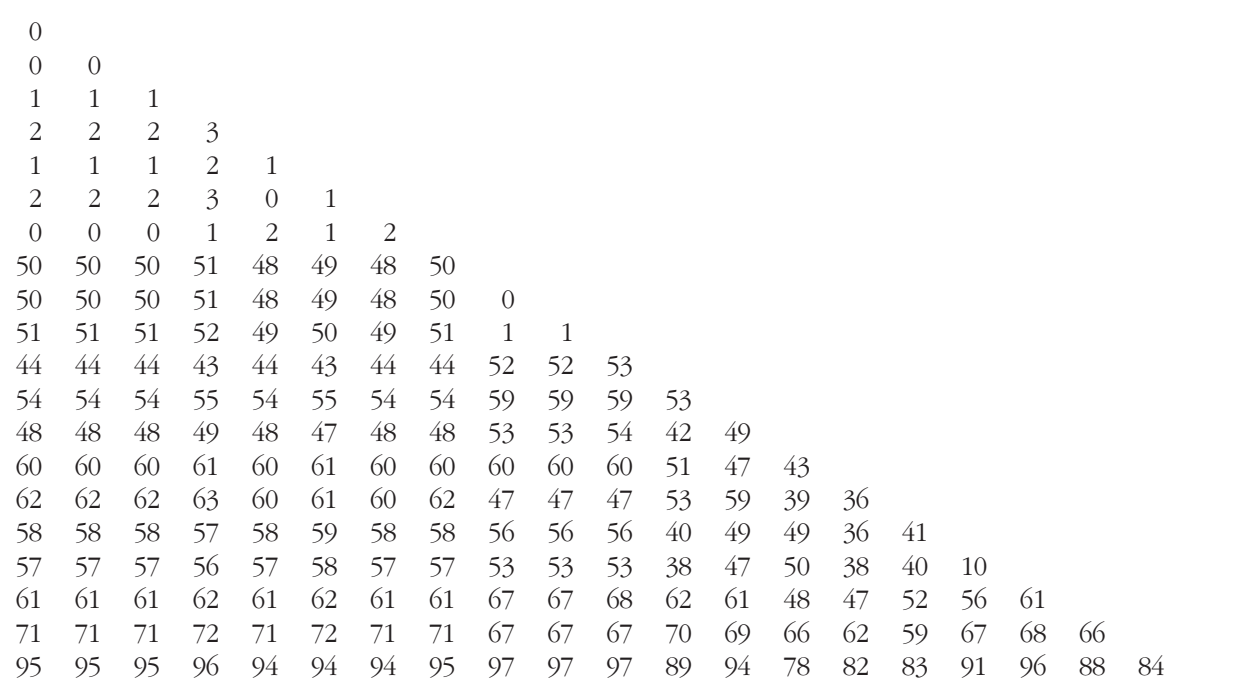

Table II. - Pairwise comparisons of the numbers of nucleotide differences over 580 sites among Onchocerca species and other filaria species.

sites of Onchocerca spp. Compared with differences among the other Onchocerca spp., equivalent differences were observed between the sequences of two Onchocerca species from wild boar. The sequences of $O$. sp. did not correspond with any of those registered in databases. The phylogenetic relationship between the two Onchocerca species from wild boar and eight other Onchocerca species is shown in Figure 1.

\section{DISCUSSION}

Tisis $\mathrm{n}$ this study, clear differences were shown in the CO1 gene sequence between $O$. dewittei japonica and O. sp. from wild boar. Ferri et al. (2009) suggested that the mitochondrial $\mathrm{CO} 1$ gene region was an appropriate genetic marker for DNA-based species identification of filarioid nematodes and detection of putative new species. According to them, if the genetic distance of the CO1 gene between two filarioid nematode specimens is greater than threshold value of $4.8 \%$, it is possible to conclude that they are different species. This standard applied to our case with a genetic distance of 8.8-9.4\%. It seems therefore reasonable to consider these two Onchocerca species from wild suids to be distinct species.

In our previous investigation to search for the potential vector of zoonotic onchocerciasis in Japan, we found three types of infective filarial larvae (designated as types I, II, and III based on their size and morphology) from wild black flies collected in a cattle shed (Takaoka \& Bain, 1990). In addition, we presumed that type II infective larva might be O. gutturosa of cattle,
O. dewittei japonica, or the unnamed Onchocerca sp. of wild boar on the basis of the morphometric observation of experimentally produced infective larvae (Fukuda et al., 2008). The present study shows that morphologically similar infective larvae of these three Onchocerca species are clearly distinguishable by comparison of their CO1 gene sequences.

According to the original description of $O$. dewittei japonica (Uni et al., 2001), the lengths of the microfilariae found from the uterus of female worms and skin of wild boar ranged between 183-210 $\mu \mathrm{m}$. The longer Onchocerca-like microfilariae (about 1.5 times the length of O. dewittei japonica) found in wild boar were provisionally referred to Onchocerca sp. in our recent study (Fukuda et al., 2008). The CO1 gene analysis of adult O. dewittei japonica confirmed that the short microfilariae from wild boar corresponded with this species. Co-infection of wild boar, Sus scrofa, and wart hog, Phacochoerus aethiopicus (Pallas, 1766), with two species of Onchocerca has been reported in Malaysia (Bain et al., 1977) and Cameroon in Africa (Bain et al., 1993). In these cases, as in Japan, microfilariae differred (long versus short) and the corresponding adults were sought but not found. In Malaysia, no transmission study was performed. In Cameroon, the two types of microfilariae had close but different Simulium vectors and the infective larvae were distinguishable (Wahl \& Bain, 1995). The present molecular analysis of Japanese material, by confirming the morphological diagnosis based on microfilariae, also supports the interpretation of dual Onchocerca infections in suids.

In conclusion, we could reliably separate $O$. dewittei japonica from $O$. sp. at the infective stage by analysis 


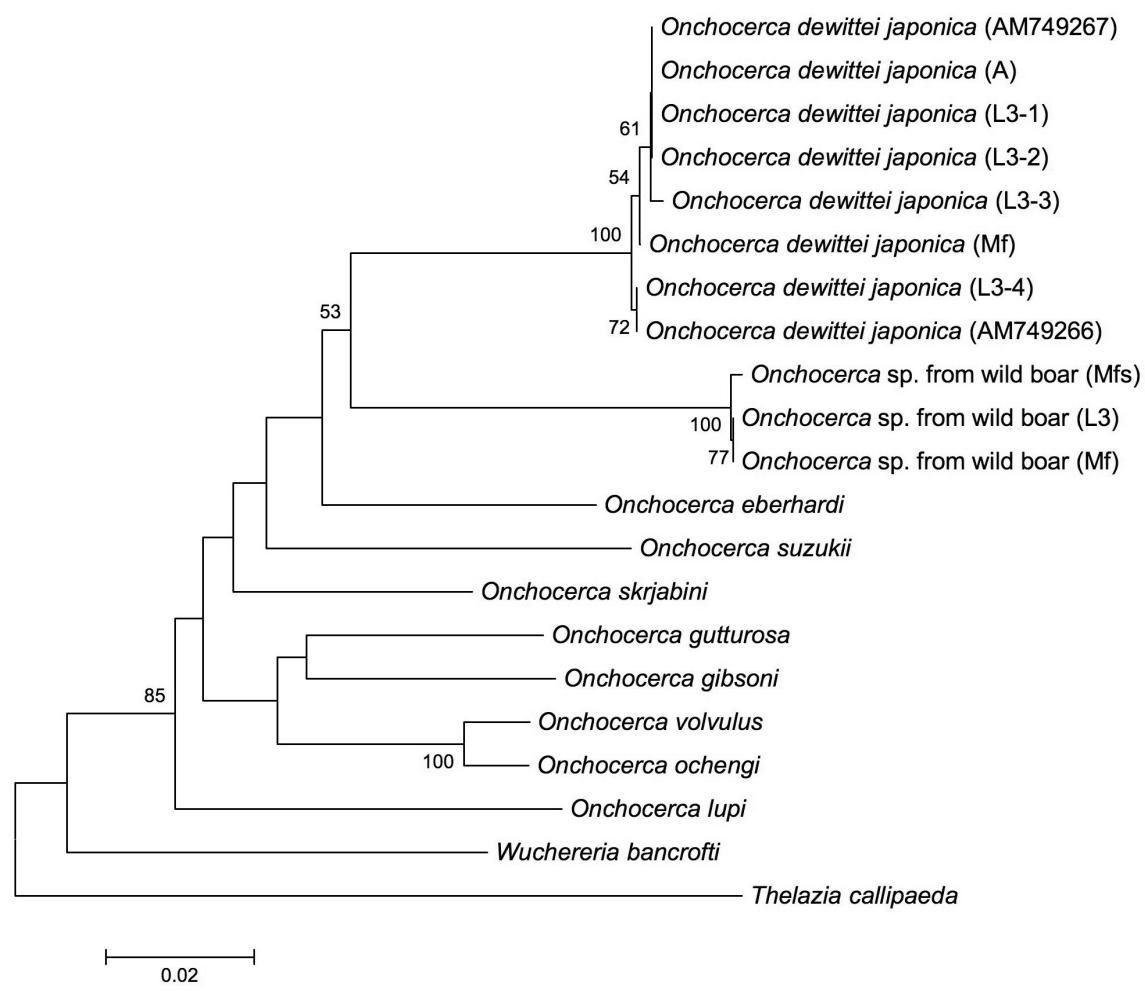

Fig. 1. - Neighbor-joining phylogenetic tree based on the partial mitochondrial CO1 gene sequences of Onchocerca spp. Numbers at the nodes are the bootstrap confidence values after 500 replicates. Values more than $50 \%$ are shown. The scale bar indicates the distance in substitutions per nucleotide. of the CO1 gene sequences. Molecular identification of three Onchocerca species including two species of wild boar, O. dewittei japonica and $O$. sp., from wildcaught black flies in Japan will be reported in a subsequent paper.

\section{ACKNOWLEDGEMENTS}

W e thank Mr H. Goto for his kindness in collecting wild boar. Our sincere thanks are due to Dr Ian Beveridge for his valuable comments on the manuscript.

\section{REFERENCES}

BaIn O., WAHL G. \& RenZ A. Onchocerca ramachandrini n. sp. from the warthog in Cameroon. Annales de Parasitologie Humaine et Comparée, 1993, 68, 139-143.

Bain O., Ramachandran C.P., Petter F. \& Mak J.W. Description d'Onchocerca dewittei n. sp. (Filarioidea) chez Sus scrofa en Malaisie. Annales de Parasitologie Humaine et Comparée, 1977, 52, 471-479.

Beaver P.C., Yoshimura H., Takayasu S., Hashimoto H. \& LiTTLE M.D. Zoonotic Onchocerca in a Japanese child. The American Journal of Tropical Medicine and Hygiene, 1989, 40, 298-300.

Casiraghi M., Anderson T.J.C., Bandi C., Bazzocchi C. \& GeNCHI C. A phylogenetic analysis of filarial nematodes: comparison with the phylogeny of Wolbachia endosymbionts. Parasite, 2001, 122, 93-103.
Ferri E., Barbuto M., Bain O., Galimberti A., Uni S., Guerrero R., Ferté H., Bandi C., Martin C. \& Casiraghi M. Integrated taxonomy: traditional approach and DNA barcoding for the identification of filarioid worms and related parasites (Nematoda). Frontiers in Zoology, 2009, 6, 1.

FuKUdA M., TAKAOKA H., UNI S. \& BAIN O. Infective larvae of five Onchocerca species from experimentally infected Simulium species in an area of zoonotic onchocerciasis in Japan. Parasite, 2008, 15, 111-119.

Hashimoto H., Murakami I., Fujiwara S., Takayasu S., Takaoka H., Uga S., AKao N., Kondo K. \& Yoshimura H. A human case of zoonotic onchocerciasis in Japan. The Journal of Dermatology, 1990, 17, 52-55.

Saitou N. \& Nei M. The neighbor-joining method: A new method for reconstructing phylogenetic trees. Molecular Biology and Evolution, 1987, 4, 406-425.

TAKAOKA H. \& BAIN O. Infections of blackflies (Diptera: Simuliidae) with three types of zoonotic Onchocerca larvae in Oita, Japan. Japanese Journal of Tropical Medicine and Hygiene, 1990, 18, 1-10.

Takaoka H., Bain O., Tajimi S., Nakayama I., Kashima K., Aoki C., Korenaga M. \& OTSuKa Y. Second case of zoonotic Onchocerca infection in a resident of Oita, Japan. Parasite, 1996, 3, 179-182.

Takaoka H., Bain O., Uni S., Korenaga M., KozeK W.J., ShiraSAKa C., AOKi C., Otsuka Y., FuKuda M., Eshita Y. \& DaA T. Zoonotic onchocerciasis caused by a parasite from wild boar in Oita, Japan: A comprehensive analysis of morphological characteristics of the worms for its diagnosis. Parasite, 2004, 11, 285-292.

Takaoka H., Bain O., Uni S., Korenaga M., Tada K., IchiKaWA H., OTSUKa Y. \& Eshita Y. Human infection with 
Onchocerca dewittei japonica, a parasite from wild boar in Oita, Japan. Parasite, 2001, 8, 261-263.

Takaoka H., Yanagi T., DaA T., Anzai S., Aoki C., Fukuda M., UNI S. \& BaIN O. An Onchocerca species of wild boar found in the subcutaneous nodule of a resident of Oita, Japan. Parasitology International, 2005, 54, 91-93.

Tamura K., Dudley J., Nei M. \& Kumar S. MEGA4: Molecular evolutionary genetics analysis (MEGA) software version 4.0. Molecular Biology and Evolution, 2007, 24, 15961599.

Uni S., Bain O., TakaOKa H., Miyashita M. \& SuzUKi Y. Onchocerca dewittei japonica n. subsp., a common parasite from wild boar in Kyushu Island, Japan. Parasite, 2001, 8, 215-222.

Wahl G. \& Bain O. Development by injection in Simulium damnosum s. 1. of two Onchocerca species from the wart hog to infective larvae resembling type D larvae (Duke, 1967). Parasite, 1995, 2, 55-62.

Reçu le 9 septembre 2009 Accepté le 2 novembre 2009 